\title{
Multidisciplinary treatments for hepatocellular carcinoma with major portal vein tumor thrombus
}

\author{
Satoshi Katagiri - Masakazu Yamamoto
}

Received: 14 August 2012/ Accepted: 23 January 2013/Published online: 17 April 2013

(C) The Author(s) 2013. This article is published with open access at Springerlink.com

\begin{abstract}
In recent years, various treatment options have become available for patients with hepatocellular carcinoma (HCC) according to the degree of background liver damage, tumor diameter and other factors associated with disease progression. Therapy has also shifted toward evidencebased treatment. Policies for the management of HCC with portal vein tumor thrombus, which has been considered an intractable condition, have not been established. Surgical resection was previously positioned as the treatment of choice, but the outcomes after resection alone were found to be disappointing. At present, multiple interdisciplinary treatments, combining resection with intra-arterial chemotherapy, radiotherapy, systemic chemotherapy and/or immunotherapy, are used on a trial-and-error basis since no standard regimens have been developed. Clinical trials of surgery combined with transarterial chemoembolization, hepatic arterial infusion of chemotherapy and radiation have obtained improved 5-year survival rates of 21.5-56 \%. The safety of surgical resection in HCC with major portal vein tumor thrombus has improved, but the optimal type(s) and timing of auxiliary therapy to use in combination with resection remain to be defined.
\end{abstract}

Keywords Hepatocellular carcinoma - Surgical treatment - Transcatheter arterial chemoembolization . Hepatic arterial infusion - Radiation - Multimodality treatment

S. Katagiri $(\bowtie) \cdot$ M. Yamamoto

Department of Surgery, Institute of Gastroenterology,

Tokyo Women's Medical University, 8-1 Kawada-cho,

Shinjuku-ku, Tokyo 162-8666, Japan

e-mail: katagiri@ige.twmu.ac.jp

\section{Introduction}

Hepatocellular carcinoma (HCC) is one of the most common malignant tumors worldwide [1]. The treatment strategies include hepatic resection, transcatheter arterial chemoembolization (TACE), percutaneous ethanol injection (PEI), microwave coagulation therapy (MCT), radiofrequency ablation (RFA), liver transplantation and systemic chemotherapy with sorafenib, an oral multikinase inhibitor [2-8]. In patients with HCC, these treatments are particularly effective for the local control of intrahepatic and extrahepatic lesions, contributing to improved cumulative survival. The mortality and morbidity rates after hepatic resection have improved in recent years because of sophisticated surgical techniques and better perioperative management [9]. However, the outcomes of patients who have HCC with portal vein tumor thrombus (PVTT) remain poor, with a mortality rate much higher than that of HCC without PVTT. The natural history of untreated nonsurgical HCC with PVTT was reported to be associated with a median survival time of 2.7 months [10]. The optimal treatment for HCC with PVTT has not been established, and only a few randomized controlled trails have been conducted. This review summarizes the current knowledge regarding multiple interdisciplinary treatments for HCC with major PVTT.

\section{Clinical features according to the macroscopic and microscopic classifications of $\mathrm{HCC}$ with PVTT}

The Liver Cancer Study Group of Japan proposed a macroscopic classification for HCC with PVTT in the General Rules for the Clinical and Pathological Study of Primary Liver Cancer [11]. This classification is 
useful, because it is based on the clinical characteristics, imaging findings, pathological findings and surgical outcomes.

PVTT is classified into five grades, Vp0-Vp4. Each grade is defined as follows: $\mathrm{Vp} 0$, no tumor thrombus in the portal vein; Vp1, presence of a tumor thrombus distal to, but not in, the second-order branches of the portal vein; $\mathrm{Vp} 2$, presence of a tumor thrombus in the second-order branches of the portal vein; $\mathrm{Vp} 3$, presence of a tumor thrombus in the first-order branches of the portal vein; and $\mathrm{Vp} 4$, presence of a tumor thrombus in the main trunk of the portal vein or a portal vein branch contralateral to the primarily involved lobe (or both).

The Liver Cancer Study Group of Japan has reported the results of the 18th follow-up survey of primary liver cancer in Japan [12]. Of 17,455 patients with HCC, 86.9, 3.0, 2.8, 3.9 and $3.3 \%$ had $\mathrm{Vp} 0, \mathrm{Vp} 1, \mathrm{Vp} 2, \mathrm{Vp} 3$ and $\mathrm{Vp} 4$, respectively, on the basis of imaging studies. Of 5,368 patients with HCC examined for the microscopic findings of surgical or biopsy specimens, 74.0, 19.0, 3.1, 2.6 and $1.4 \%$ had grade $\mathrm{Vp} 0, \mathrm{Vp} 1, \mathrm{Vp} 2, \mathrm{Vp} 3$ and $\mathrm{Vp} 4$ disease, respectively. Of 25,066 patients with HCC treated by hepatic resection between 1994 and 2005, the 5-year cumulative survival rates were 59.0, 39.1, 23.3 and $18.3 \%$ in patients with $\mathrm{Vp} 0, \mathrm{Vp} 1, \mathrm{Vp} 2$, and $\mathrm{Vp} 3$ or Vp4 grade disease, respectively (Fig. 1). In the earlier 15 th follow-up survey of primary liver cancer conducted in 21,711 patients with HCC treated by hepatic resection between 1988 and 1999, the 5-year cumulative survival rates were 56.5, 34.4, 27.0 and $17.3 \%$ in patients with $\mathrm{Vp} 0, \mathrm{Vp} 1, \mathrm{Vp} 2$ and $\mathrm{Vp} 3$ or $\mathrm{Vp} 4$ grade disease, respectively (Fig. 2) [13]. The results of these surveys indicate that the recent surgical outcomes in patients with $\mathrm{Vp} 2$ and $\mathrm{Vp} 3$ or $\mathrm{Vp} 4$ disease have not improved significantly in Japan during the last 6 years.

\section{Hepatectomy}

In the 1980s, surgical resection was indicated only for patients with a tumor thrombus in a first-order branch of the portal vein, not involving the confluence of the right and left portal veins [14, 15]. Beginning in the 1990s, surgical resection of a tumor thrombus extending to the main portal trunk was reported by Kumada et al. and Yamaoka et al. [16, 17]. The technique was gradually refined and standardized to become the currently used procedure. The results of surgical resection reported in 2000, and subsequently in patients with a PVTT classification of $\mathrm{Vp} 3$ and $\mathrm{Vp} 4$, are shown in Table 1 [12, 18-26]. These studies basically summarized the outcomes of surgical therapy as the initial treatment after the diagnosis of PVTT, and studies in which patients received pretreatment are not included. The mortality ranged from 0 to $11.5 \%$, and was less than $5 \%$ in seven of the nine studies in which mortality data were reported. The 5-year survival rates ranged from 0 to $39 \%$. Although these outcomes were not necessarily the results of resection alone, $\mathrm{Wu}$ et al. [18], Inoue et al. [23] and Ban et al. [25] obtained higher 5-year survival rates exceeding $20 \%$. The Liver Cancer Study Group of Japan reported survival rates of $18.3 \%$ at 5 years and $8.4 \%$ at 10 years in the 18th follow-up survey of primary liver cancer in Japan, encompassing 1,021 patients who underwent $\mathrm{Vp} 3$ or $\mathrm{Vp} 4$ resection.

\section{Transcatheter arterial chemoembolization and hepatic arterial infusion chemotherapy}

TACE is a key treatment for patients with unresectable HCC. However, TACE had previously been contraindicated in patients with PVTT involving the main trunk or a
Fig. 1 Eighteenth follow-up survey of primary liver cancer conducted in 25,066 patients with HCC treated by hepatic resection between 1994 and 2005. Vp0 no tumor thrombus; Vp1 tumor thrombus distal to the second-order branches of the portal vein, but not involving the second-order branches; $V p 2$ tumor thrombus in the secondorder branches of the portal vein; $V p 3$ tumor thrombus in the first-order branches of the portal vein and/or the main trunk of the portal vein and/or contralateral portal vein branch to the primarily involved

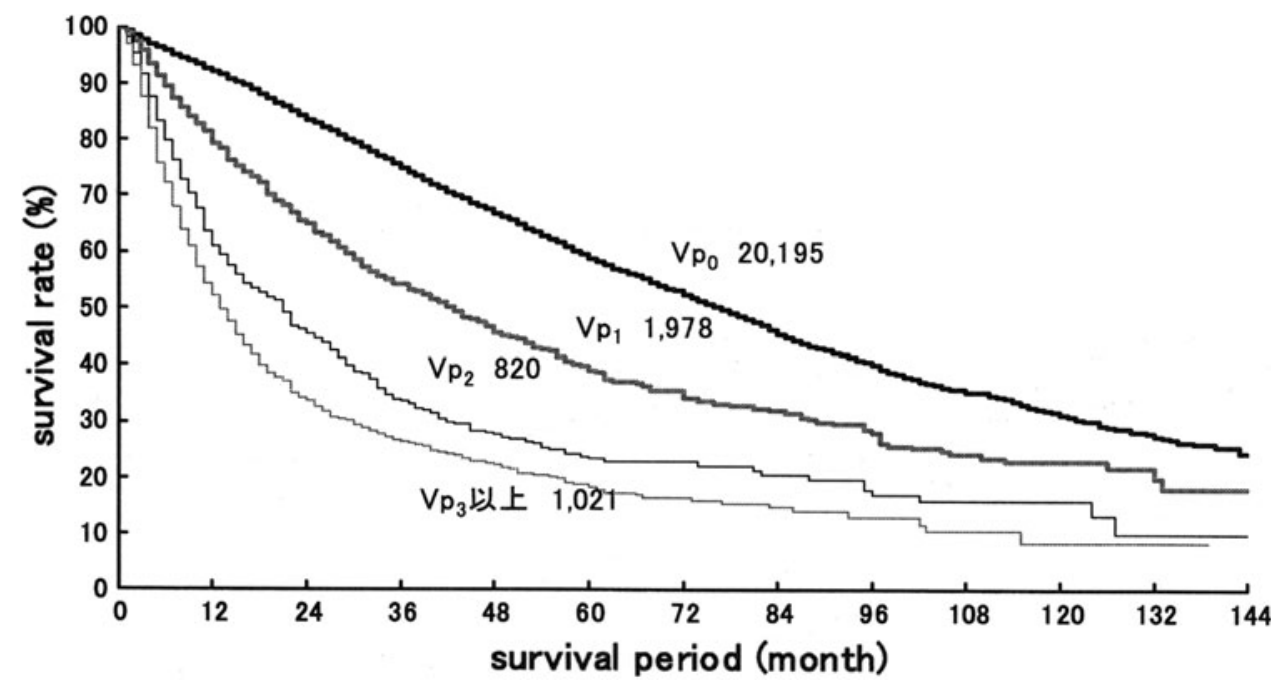


Fig. 2 Fifteenth follow-up survey of primary liver cancer conducted in 21,711 patients with HCC treated by hepatic resection between 1988 and 1999. VpO no tumor thrombus; Vpl tumor thrombus distal to the second-order branches of the portal vein, but not involving the second-order branches; $V p 2$ tumor thrombus in the secondorder branches of the portal vein; $V p 3$ tumor thrombus in the first-order branches of the portal vein and/or the main trunk of the portal vein and/or contralateral portal vein branch to the primarily involved

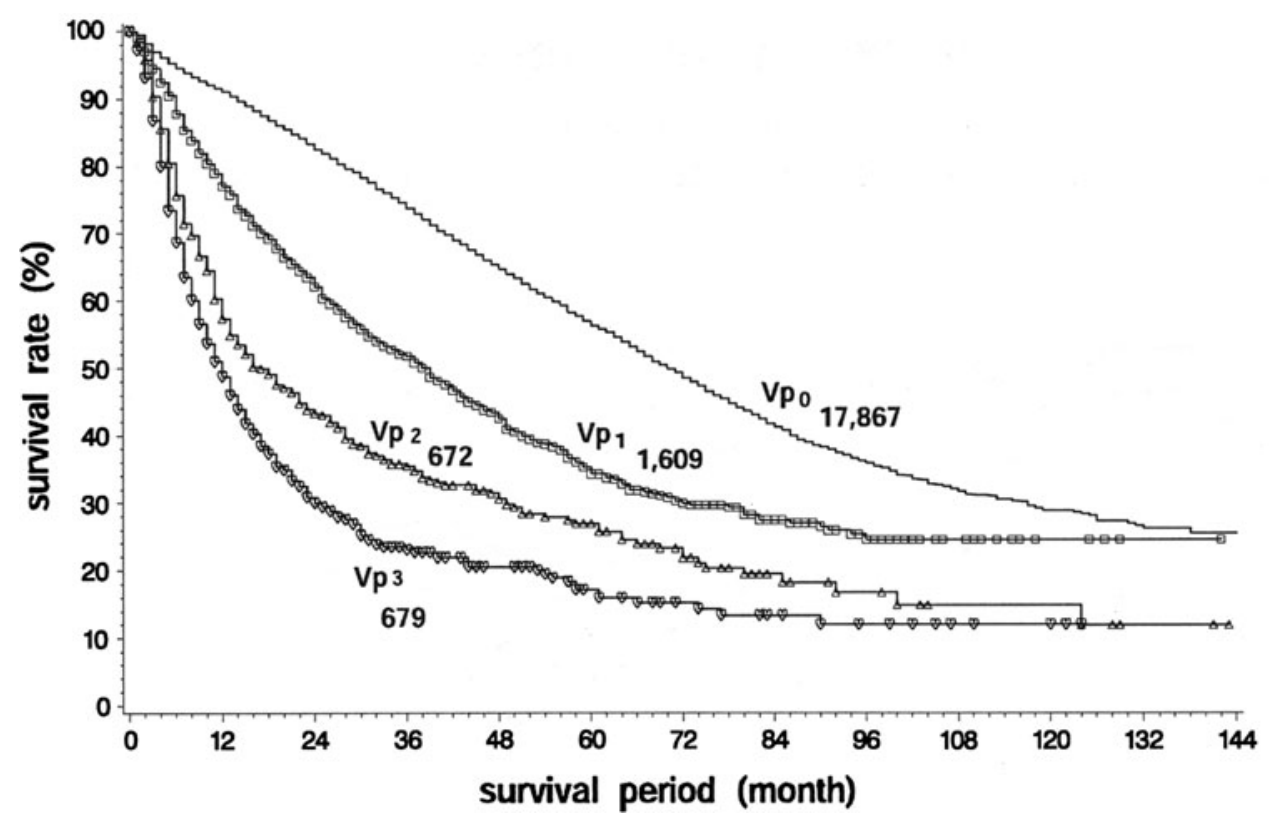

Table 1 Hepatectomy in patients with HCC and major PVTT

\begin{tabular}{|c|c|c|c|c|c|c|}
\hline First author & Year & No. & Clarification of PVTT & Mortality & 5-year survival rate & Median survival time \\
\hline Wu [18] & 2000 & 15 & $\mathrm{Vp} 4$ & $0 \%$ & $26.4 \%$ & NA \\
\hline Poon [19] & 2003 & 20 & Vp 3-4 & $5.7 \%$ & $13.3 \%$ & $6.0 \mathrm{mo}$ \\
\hline Ikai [20] & 2006 & 78 & Vp 3-4 & $3.8 \%$ & $10.9 \%$ & $8.9 \mathrm{mo}$ \\
\hline Treut [21] & 2006 & 26 & Vp 3-4 (or Vv) & $11.5 \%$ & $13.0 \%$ & $9.0 \mathrm{mo}$ \\
\hline Chen [22] & 2006 & 152 & Vp 4 & $2.6 \%$ & $0 \%$ & $10.1 \mathrm{mo}$ \\
\hline Inoue [23] & 2009 & 20 & Vp 4 & $0 \%$ & $39.0 \%$ & NA \\
\hline Kondo [24] & 2009 & 5 & Vp 4 & $0 \%$ & $0 \%$ & $8.0 \mathrm{mo}$ \\
\hline Ban [25] & 2009 & 45 & Vp 3-4 & $0 \%$ & $22.4 \%$ & $20.0 \mathrm{mo}$ \\
\hline \multirow[t]{2}{*}{ Shi [26] } & 2010 & 247 & Vp 3 (169) & $0.6 \%$ & $17.7 \%$ (3-year) & $15.0 \mathrm{mo}$ \\
\hline & & & Vp 4 (78) & $0 \%$ & $3.6 \%$ (3-year) & $10.0 \mathrm{mo}$ \\
\hline Ikai [12] & 2010 & 1,021 & Vp 3-4 & NA & $18.3 \%$ & NA \\
\hline
\end{tabular}

$V p 3$ tumor thrombus in first-order branches of the portal vein, $V p 4$ tumor thrombus in the main trunk of the portal vein and/or contralateral portal vein branch to the primarily involved lobe, $N A$ not available, mo months, $V v$ tumor thrombus in the hepatic vein

first-order left or right branch of the portal vein [27, 28]. In 1997, Lee et al. [29] reported that TACE could be safely performed even in HCC associated with occlusion of the main trunk of the portal vein owing to the presence of collateral circulation. Table 2 shows the results of TACE and hepatic arterial infusion (HAI) chemotherapy in patients who had HCC with high-grade PVTT, reported after 2000 [30-35]. The majority of studies used HAI with a combination of cisplatin and 5-fluorouracil, rather than TACE or transcatheter arterial embolization (TAE). The best results were obtained by Ando et al., who treated 48 patients with Vp2 to Vp4 PVTT by HAI with cisplatin plus 5 -fluorouracil. The 5-year overall survival rate was $11.0 \%$, and the median survival time was 10.2 months in that study [31]. Many of the other studies reported overall survival of up to 3 years, but the long-term outcomes remain largely unclear. The median survival time ranged from 3.5 to 9.5 months, and fell short of 1 year. Although the background characteristics of the study groups differed, there was an overall trend toward shorter survival of patients who underwent HAI compared with studies of patients who underwent surgical resection.

\section{Radiotherapy and ablation therapy}

The results of a study in which radiotherapy was used to treat PVTT were reported by Chen et al. [36] in 1994. Ten patients were treated, and the response rate was $100 \%$. Pilot and other studies followed, and many reports 
Table 2 Transcatheter arterial chemoembolization and hepatic arterial infusion chemotherapy in patients with HCC and major PVTT

\begin{tabular}{lcclllll}
\hline First author & Year & No. & Classification of PVTT & Treatment & & Survival rate & Median survival time \\
\hline Itamoto [30] & 2002 & 7 & Vp 3-4 & HAI & CDDP + 5-FU & NA & 7.5 mo \\
Ando [31] & 2002 & 48 & Vp 2-4 & HAI & CDDP + 5-FU & $11.0 \%(5$-year) & 10.2 mo \\
Izaki [32] & 2004 & 15 & Vp 2-4 & GIA-TAE (10) & & $13.3 \%(3-$ year) & 9.5 mo \\
& & & & GIA-TAE + RT (5) & $0 \%(3$-year) & 7.1 mo \\
Georgiades [33] & 2005 & 32 & Vp 3-4 & TACE & CDDP + 5FU (10) & NA & 3.5 mo \\
Akiyama [34] & 2008 & 23 & Vp 3-4 & HAI & Control (13) & NA & 2.2 mo \\
& & & & HAI & CDDP powder & $16 \%(2$-year) & 7.0 mo \\
Kondo [35] & 2010 & 24 & Vp 1-4 & & &
\end{tabular}

$V p 1$ tumor thrombus distal to the second-order branches of the portal vein, but not involving the second-order branches; $V p 2$ tumor thrombus in the second-order branches of the portal vein; $V p 3$ tumor thrombus in the first-order branches of the portal vein; $V p 4$ tumor thrombus in the main trunk of the portal vein and/or contralateral portal vein branch to the primarily involved lobe; HAI hepatic arterial infusion; $C D D P$ cisplatin; 5FU 5-fluorouracil; NA not available; mo, months; GIA-TAE transcatheter arterial embolization with gelatin sponge immersed in an anticancer agent; $R T$ radiation therapy; $T A C E$ transcatheter arterial chemoembolization

appeared after 2000. The studies of radiotherapy and ablation therapy that were reported in 2005 and subsequently are shown in Table 3 [37-45].

Three-dimensional conformal radiotherapy (3D-CRT) was used in four studies [38, 40, 41, 43], and photon beam therapy [37], iodine-125 seed implantation [42], percutaneous radiofrequency ablation [44] and percutaneous laser ablation [45] were used in one study each. The overall survival rates at 5 years were reported only by Hata et al. [37] and Nakagawa et al. [38] and were 24 and $5.1 \%$, respectively. The longest median survival times were obtained by Hata et al. (11 months) [37], Lin et al. (10.7 months) [41] and Shirai et al. (10.3 months) [43], but were all less than 1 year. Zeng et al. [39] showed that radiotherapy combined with supportive care, TACE or hepatic resection significantly improved the outcomes in a study of 158 patients with HCC with portal vein and/or inferior vena cava tumor thrombus. In a multivariate analysis, the presence or absence of radiotherapy was clearly shown to be a significant determinant of survival. This study provided evidence supporting the therapeutic effectiveness of multimodality treatment.

\section{Nonsurgical multimodality treatment}

Multimodality treatment is clearly essential for the management of HCC and is of particularly high value in cases of HCC with PVTT. Table 4 lists the studies of nonsurgical interdisciplinary treatment in patients with HCC and PVTT

Table 3 Radiotherapy and ablation therapy in patients with HCC and major PVTT

\begin{tabular}{lccllll}
\hline First author & year & No. & Classification of PVTT & Treatment & Survival rate & Median survival time \\
\hline Hata [37] & 2005 & 12 & Vp 3-4 & Proton beam therapy (50-72 Gv) & 24 \% (5-year) & 11 mo (CR + PR) \\
Nakagawa [38] & 2005 & 52 & Vp 2-4 & 3D-CRT (39-60 Gy) & 5.1 \% (5-year) & NA \\
Zeng [39] & 2005 & 44 & Vp 1-4, Vv3 & External beam radiation (36-60 Gy) & 34.8 \% (1-year) & 8.0 mo \\
Kim [40] & 2005 & 59 & Vp 3-4 & 3D-CRT (39-70.2 Gy) & 20.7 \% (2-year) & 10.7 mo (CR + P) \\
Lin [41] [RCT] & 2006 & 43 & Vp 3-4 & Stereotactic radiotherapy (22) & NA & 6.0 mo \\
& & & & 3D-CRT (21) & NA & 6.7 mo \\
Zhang [42] & 2008 & 10 & Vp 3 & 125-iodine seed implantation for PVTT & NA & NA \\
Shirai [42] & 2009 & 26 & Vp 3-4 & 3D-CRT using SPECT & 30 \% (2-year) & 10.3 mo \\
Giorgio [44] & 2009 & 13 & Vp 4 & Percutaneous RFA & 77 \% (3-year) & NA \\
Zheng [45] & 2009 & 108 & Vp 3-4 & Percutaneous laser ablation & 22.38 \% (3-year) & NA \\
\hline
\end{tabular}

$V p 1$ tumor thrombus distal to the second-order branches of the portal vein, but not involving the second-order branches; $V p 2$ tumor thrombus in the second-order branches of the portal vein; $V p 3$ tumor thrombus in the first-order branches of the portal vein; $V p 4$ tumor thrombus in the main trunk of the portal vein and/or contralateral portal vein branch to the primarily involved lobe; mo months; $C R$ complete response; $P R$ partial response; $3 D$-CRT three-dimensional conformal radiotherapy; $N A$ not available; $V v$ tumor thrombus in the hepatic vein; $R C T$ randomized control study; SPECT single photon emission computed tomography; RFA radiofrequency ablation therapy 
Table 4 Nonsurgical interdisciplinary treatment in patients with HCC and major PVTT

\begin{tabular}{|c|c|c|c|c|c|c|}
\hline First author & Year & No. & $\begin{array}{l}\text { Classification } \\
\text { of PVTT }\end{array}$ & $\begin{array}{l}\text { Multimodality } \\
\text { treatment }\end{array}$ & Survival rate & $\begin{array}{l}\text { Median } \\
\text { survival time }\end{array}$ \\
\hline Kaneko [46] & 2001 & 8 & Vp 3-4 & HAI: CDDP,5-FU, MTX + IFM- $\alpha+$ Leu & $15 \%$ (2-year) & $11 \mathrm{mo}(\mathrm{CR}+\mathrm{PR})$ \\
\hline Sakon [47] & 2002 & 8 & Vp 3-4 & HAI: $5-\mathrm{FU}+\mathrm{IFN}-\alpha$ & NA & NA \\
\hline Ishikura [48] & 2002 & 20 & Vp 3-4 & TACE $\rightarrow$ RT (50 Gy) & $25 \%$ (1-year) & $5.3 \mathrm{mo}$ \\
\hline Yamada [49] & 2003 & 19 & Vp 3-4 & $\mathrm{TACE} \rightarrow$ 3D-CRT & $10.2 \%$ (2-year) & $7.0 \mathrm{mo}$ \\
\hline Ota $[50]$ & 2005 & 55 & Vp 3-4 & HAI: 5 -FU + IFN- $\alpha$ & $164 \%$ (5-year) & $11.8 \mathrm{mo}$ \\
\hline Hsu [51] & 2006 & 20 & Vp 3-4 & 3D-CRT + thalidomide & $0 \%$ (5-year) & NA \\
\hline Obi [52] & 2006 & 116 & Vp 3-4 & HAI: 5 -FU + IEN- $\alpha$ & $18 \%$ (2-year) & $6.9 \mathrm{mo}$ \\
\hline Ishikawa [53] & 2007 & 10 & Vp 3-4 & HAI: etoposide, carboplatin, epirubicin, 5FU $\rightarrow$ UFT-E & $20 \%$ (2-year) & $14.7 \mathrm{mo}$ \\
\hline Kitamura [54] & 2009 & 32 & Vp 3-4 & $\begin{array}{l}\text { HAI: } 5-\mathrm{FU}+\mathrm{IFN}-\alpha+3 \mathrm{D}-\mathrm{CRT}(16) \\
\text { HAI: } 5-\mathrm{FU}+\mathrm{IFN}-\alpha(16)\end{array}$ & $\begin{array}{l}\text { NA } \\
\text { NA }\end{array}$ & $\begin{array}{l}7.5 \mathrm{mo} \\
7.9 \mathrm{mo}\end{array}$ \\
\hline Zhang [55] & 2009 & 45 & Vp 4 & $\begin{array}{l}\text { PTPVS-TACE } \rightarrow \text { 3D-CRT (16) } \\
\text { PTPVA-TACE (29) }\end{array}$ & $\begin{array}{l}32.5 \% \text { (360-day) } \\
6.9 \% \text { (360-day) }\end{array}$ & $\begin{array}{l}\text { NA } \\
\text { NA }\end{array}$ \\
\hline Luo [56] & 2010 & 32 & Vp 3-4 & 125-iodine seed strand + Stent & $39.3 \%$ (360-day) & $8.4 \mathrm{mo}$ \\
\hline
\end{tabular}

$V p 3$ tumor thrombus in first-order branches of the portal vein, $V p 4$ tumor thrombus in the main trunk of the portal vein and/or contralateral portal vein branch to the primarily involved lobe, $H A I$ hepatic artery infusion chemotherapy, $C D D P$ cisplatin, 5-FU 5-fluorouracil, $M T X$ methotrexate, $I F N-\alpha$ interferon- $\alpha$, Leu leucovorin, mo months, $C R$ complete response, $P R$ partial response, $N A$ not available, TACE transcatheter arterial chemoembolization, $R T$ radiotherapy, $3 D$-CRT three-dimensional conformal radiotherapy, UFT-E enteric-coated tegafur/uracil, $P T P V S$ percutaneous transhepatic portal vein stenting

[46-56]. The multimodality treatment consisted of HAI plus interferon in five studies [46, 47, 50, 52, 54], HAI with enteric-coated tegafur/uracil (UFT) in one study [53], a combination of 3D-CRT and thalidomide in one study [51], 3D-CRT after TACE in one study [49], radiotherapy after TACE in one study [48], HAI and 3D-CRT combined with interferon in one study [54], TACE after percutaneous transhepatic portal vein stenting (PTPVS) in one study [55], TACE and 3D-CRT after PTPVS in one study [56] and iodine-125 seed strands after PTPVS in one study [56]. The 5-year overall survival rate was $16.4 \%$ in the study of HAI plus interferon reported by Ota et al. [50]. Among the reports on the various types of multimodality treatment, the longest median survival times were obtained by Ota et al. (11.8 months) [50] and in the HAI plus UFT study by Ishikawa et al. (14.7 months) [53]. The investigation by Ota et al. [50] had a relatively large study group and good long-term survival, and is thus considered a valuable clinical trial.

\section{Surgical multimodality treatment}

Although direct comparisons of the outcomes of treatment are precluded by the differences in the patients' background characteristics, hepatectomy appears to provide better outcomes than TACE, TAI, radiotherapy, ablation therapy and nonsurgical multimodality treatment. Table 5 presents the studies of hepatectomy-based interdisciplinary treatment for HCC with PVTT [57-64]. The main treatments used were hepatic resection after TACE in one study; TACE, HAI, and portal vein infusion (PVI) chemotherapy after hepatic resection in three studies; preoperative intravenous chemotherapy with doxorubicin, cisplatin and 5-fluorouracil plus subcutaneous interferon- $\alpha$ (PIAF) or yttrium-90 plus doxorubicin in one study; postoperative percutaneous isolated hepatic perfusion (PIHP) in one study; interferon with 5-fluorouracil after hepatic resection in one study; and hepatic resection after radiotherapy in one study. Hepatic resection was performed before the other treatments in five studies. The 5-year survival rates were reported for all but one study, and were good, ranging from 21.5 to $56 \%$. The highest rate of $56 \%$ was obtained by Lau et al. [60] in a small study of only seven patients. However, these results were very encouraging. The median survival time after hepatectomy-based multimodality treatment ranged from 13.0 to 22.1 months, suggesting that interdisciplinary therapy contributed to improved long-term survival. In a controlled trial by Peng et al., 126 patients with HCC and PVTT were randomly assigned to hepatectomy alone (control group) or hepatectomy followed by TACE (TACE group). The median survival time was 13 months in the TACE group and 9 months in the control group. The estimated survival rates at 5 years were also better in the TACE group $(21.5 \%)$ than in the control group $(8.5 \%)$. This randomized controlled study of multimodality treatment is considered to be a key clinical trial. The available evidence indicates that hepatectomy-based interdisciplinary therapy is effective and should be explored in further trials. 
Table 5 Surgical interdisciplinary treatment it patients with HCC and major PVTT

\begin{tabular}{|c|c|c|c|c|c|c|}
\hline First author & Year & No. & $\begin{array}{l}\text { Classification } \\
\text { of PVTT }\end{array}$ & $\begin{array}{l}\text { Multimodality treatment } \\
\text { and hepatic reaction }\end{array}$ & 5-year survival rate & Median survival time \\
\hline \multirow[t]{2}{*}{ Minagawa [57] } & 2001 & 45 & Vp 2-4 & Pre-TACE $\rightarrow$ Hr (18) & $42 \%$ & NA \\
\hline & & & & TACE or HAI (27) & $0 \%$ & NA \\
\hline \multirow[t]{4}{*}{ Fan $[58]$} & 2001 & 147 & Vp 3-4 & Conservative (18) & $0 \%$ & $2.0 \mathrm{mo}$ \\
\hline & & & & HAL and/or Post-HAI, PVI (18) & $0 \%$ & $5.0 \mathrm{mo}$ \\
\hline & & & & $\operatorname{Hr}(79)$ & $16.6 \%$ & $12.0 \mathrm{mo}$ \\
\hline & & & & $\mathrm{Hr} \rightarrow$ Post-TACE or HAI and/or PVI (32) & 26.8 & $16.0 \mathrm{mo}$ \\
\hline Fukuda [59] & 2002 & 19 & Vp 3-4 or Vv or B & $\mathrm{Hr} \rightarrow$ Post-HAI or TACE etc. & $36.3 \%$ & $22.1 \mathrm{mo}$ \\
\hline Lau [60] & 2004 & 7 & Vp 4 & Pre-PIAF or yttrium $90+$ Dox $\rightarrow \mathrm{Hr}$ & $56 \%$ & NA \\
\hline $\mathrm{Ku}[61]$ & 2004 & 17 & Vp 1-4 & $\mathrm{Hr} \rightarrow$ Post-PIHP & $40 \%$ & NA \\
\hline Nagano [62] & 2007 & 30 & Vp 4 & $\mathrm{Hr} \rightarrow$ Post-IFN/5-FU & $21.4 \%$ (3-year) & $9.5 \mathrm{mo}$ \\
\hline \multirow[t]{2}{*}{ Kamiyama [63] } & 2007 & 43 & Vp 3-4 & Pre-RT $\rightarrow$ Hr (15) & $34.8 \%$ & $19.6 \mathrm{mo}$ \\
\hline & & & & $\operatorname{Hr}(28)$ & $13.1 \%$ & $9.1 \mathrm{mo}$ \\
\hline \multirow[t]{2}{*}{ Peng [64] [RCT] } & 2009 & 126 & Vp 3-4 & $\operatorname{Hr}(53)$ & 8.5 & $9.0 \mathrm{mo}$ \\
\hline & & & & $\mathrm{Hr} \rightarrow$ Post-TACE $(51)$ & $21.5 \%$ & $13.0 \mathrm{mo}$ \\
\hline
\end{tabular}

$V p 1$ tumor thrombus in distal to the second-order branches of the portal vein, but not of the second-order branches; $V p 2$ tumor thrombus in the second-order branches of the portal vein; $V p 3$ tumor thrombus in the first-order branches of the portal vein; $V p 4$ tumor thrombus in the main trunk of the portal vein and/or contralateral portal vein branch to the primarily involved lobe; TACE transcatheter arterial chemoembolization; $H r$ hepatic resection; NA not available; HAI hepatic artery infusion chemotherapy; HAL hepatic artery ligation; PVI portal vein infusion chemotherapy; $V v$ tumor thrombus in the hepatic vein; $B$ tumor thrombus in the bile duct; PIAF doxorubicin, cisplatin, 5 -fluorouracil iv + interferon- $\alpha$ sc; Dox doxorubicin; PIHP percutaneous isolated hepatic perfusion; IFN interferon- $\alpha$; 5-FU 5-fluorouracil; $R T$ radiotherapy; $R C T$ randomized control study

\section{Conclusions}

No curative treatment is currently available for HCC with major PVTT. However, a growing body of evidence suggests that hepatectomy- and thrombectomy-based multiple interdisciplinary treatments are effective options. The details and optimal timing of auxiliary treatments combined with hepatectomy and thrombectomy in patients with HCC and PVTT remain an important topic for future research. Future recommendations must be based on clear evidence from large, well-controlled clinical trials.

Open Access This article is distributed under the terms of the Creative Commons Attribution License which permits any use, distribution, and reproduction in any medium, provided the original author(s) and the source are credited.

\section{References}

1. Blum HE. Hepatocellular carcinoma: therapy and prevention. World J Gastroenterol. 2005;11:7391-400.

2. Fan ST, Lo CM, Liu CL, Lam CM, Yuen WK, Yeung C, et al. Hepatectomy for hepatocellular carcinoma: toward zero hospital deaths. Ann Surg. 1999;229:322-30.

3. Matsui O, Kadoya M, Yoshikawa J, Gabta T, Arai K, Demachi H, et al. Small hepatocellular carcinoma: treatment with subsegmental transcatheter arterial embolization. Radiology. 1993;188: 79-83.

4. Ebara M, Ohta M, Sugiura N, Kita K, Yoshikawa M, Okuda K, et al. Percutaneous ethanol injection for the treatment of small hepatocellular carcinoma. Study of 95 patients. J Gastroenterol Hepatol. 1990;5:616-26.

5. Seki T, Wakabayashi M, Nakagawa T, Itho T, Shiro T, Kunieda K, et al. Ultrasonically guided percutaneous microwave coagulation therapy for small hepatocellular carcinoma. Cancer. 1994;74:817-25.

6. Livraghi T, Goldberg SN, Lazzaroni S, Meloni F, Solbiati L, Gazelle GS. Small hepatocellular carcinoma: treatment with radio-frequency ablation versus ethanol injection. Radiology. 1999;210:655-61.

7. Penn I. Hepatic transplantation for primary and metastatic cancer of the liver. Surgery. 1991;110:726-35.

8. Llovet JM, Ricci S, Mazzaferro V, Hilgard P, Gane E, Blanc JF, et al. Sorafenib in advanced hepatocellular carcinoma. N Engl J Med. 2008:359:378-90.

9. Itoh S, Shirabe K, Taketomi A, Morita K, Harimoto N, Tsujita E, et al. Zero mortality in more than 300 hepatic resections: validity of preoperative volumetric analysis. Surg Today. 2012;42:435-40.

10. Llovet JM, Bustamante J, Castells A, Vilana R, Ayuso Mdel C, Sala M, et al. Natural history of untreated nonsurgical hepatocellular carcinoma: rationale for the design and evaluation of therapeutic trials. Hepatology. 1999;29:62-7.

11. Liver Cancer Study Group of Japan. The general rules for the clinical and pathological study of primary liver cancer, second english edition. Tokyo: Kanehara \& Co., Ltd.; 2003.

12. Ikai I, Kudo M, Arii S, Omata M, Kojiro M, Sakamoto M, et al. Report of the $18^{\text {th }}$ follow-up survey of primary liver cancer in Japan. Hepatol Res. 2010;40:1043-69.

13. Ikai I, Itai Y, Okita K, Omata M, Kojiro M, Kobayashi K, et al. Report of the $15^{\text {th }}$ follow-up survey of primary liver cancer in Japan. Hepatol Res. 2004;28:21-9.

14. Lee NW, Wong J, Ong GB. The surgical management of primary carcinoma of the liver. World J Surg. 1982;6:66-75.

15. Lin TY, Lee CS, Chen KM, Chen CC. Role of surgery in the treatment of primary carcinoma of the liver: a 31-year experience. Br J Surg. 1987;74:839-42. 
16. Kumada K, Ozawa K, Okamoto R, Takayasu T, Yamaguchi M, Yamamoto $\mathrm{T}$, et al. Hepatic resection of hepatocellular carcinoma with removal of portal vein tumor thrombi. Surgery. 1990; 108:821-7.

17. Yamaoka Y, Kumada K, Ino K, Takayasu T, Shimahara Y, Mori $\mathrm{K}$, et al. Liver resection for hepatocellular carcinoma with direct removal of tumor thrombi in the main portal vein. World J Surg. 1992;16:1172-7.

18. Wu CC, Hsieh SR, Chen JT, Ho WL, Lin MC, Yeh DC, et al. An appraisal of liver and portal vein resection for hepatocellular carcinoma with tumor thrombi extending to portal bifurcation. Arch Surg. 2000;135:1273-9.

19. Poon RT, Fan ST, Hg IO, Wong J. Prognosis after hepatic resection for stage IVA hepatocellular carcinoma: a need for classification. Ann Surg. 2003;240:299-305.

20. Ikai I, Hatano E, Hasegawa S, Fijii H, Taura K, Uyama N, et al. Prognostic index for patients with hepatocellular carcinoma combined with tumor thrombosis in the major portal vein. J Am Coll Surg. 2006;202:431-8.

21. Le Treut YP, Hardwigsen J, Ananian P, Saisse J, Gregoire E, Richa H, et al. Resection of hepatocellular carcinoma with tumor thrombus in the major vasculature. A European case-control series. J Gastrointest Surg. 2006;10:855-62.

22. Chen XP, Qiu FZ, Wu ZD, Zhang ZW, Haung ZY, Chen YF, et al. Effects of location end extension of portal vein tumor thrombus on long-term outcomes of surgery treatment for hepatocellular carcinoma. Ann Surg Oncol. 2007;13:940-6.

23. Inoue Y, Hasegawa K, Ishizuka T, Aoki T, Sano K, Beck Y, et al. Is there any difference in survival according to the portal tumor thrombectomy method in patients with hepatocellular carcinoma? Surgery. 2009;145:9-19.

24. Kondo K, Chijiiwa K, Kai M, Otani K, Nagaike K, Ohuchida J, et al. Surgical strategy for hepatocellular carcinoma patients with portal vein tumor thrombus based on prognostic factors. J Gastrointest Surg. 2009;13:1078-83.

25. Ban D, Shimada K, Yamamoto Y, Nora S, Esaki M, Sakamoto Y, et al. Efficacy of a hepatectomy and a tumor thrombectomy for hepatocellular carcinoma with tumor thrombus extending to the main portal vein. J Gastrointest Surg. 2009;13:1921-8.

26. Shi J, Lai EC, Li N, Guo WX, Xue J, Lau WY, et al. Surgical treatment of hepatocellular carcinoma with portal vein tumor thrombus. Ann Surg Oncol. 2010;17:2073-80.

27. Yamada R, Sato M, Kawabata M, Nakatsuka H, Nakamura K, Takashima S. Hepatic artery embolization in 120 patients with unresectable hepatoma. Radiology. 1983;148:397-401.

28. Allison DJ, Jordan H, Hennessy H. Therapeutic embolization of the hepatic artery. A review of 75 procedures. Lancet. 1985;1:595-9.

29. Lee HS, Kim JS, Choi IIJ, Chung JW, Park JH, Kim CY. The safety and efficacy of transcatheter arterial chemoembolization in the treatment of patients with hepatocellular carcinoma and main portal vein obstruction: a prospective controlled study. Cancer. 1997;79:2087-94.

30. Itamoto T, Nakahara H, Tashiro H, Haruta N, Asahara T, Naito A, et al. Hepatic arterial infusion of 5-fluorouracil and cisplatin for unresectable or recurrent hepatocellular carcinoma with tumor thrombus of the portal vein. J Surg Oncol. 2002;80:143-8.

31. Ando E, Tanaka M, Yamashita F, Kuromatsu R, Yutani S, Fukumori K, et al. Hepatic arterial infusion chemotherapy for advanced hepatocellular carcinoma with portal vein tumor thrombosis. Cancer. 2002;95:588-95.

32. Izaki K, Sugimoto K, Sugiura K, Hirota S. Transcatheter arterial embolization for advanced tumor thrombus with marked arterioportal or arteriovenous shunt complicating hepatocellular carcinoma. Radiat Med. 2004;22:155-62.

33. Georgiades CS, Hong K, D'Angelo M, Geschwind JF. Safety and efficacy of transarterial chemoembolization in patients with unresectable hepatocellular carcinoma and portal vein thrombosis. J Vas Interv Radiol. 2005;16:1653-9.

34. Akiyama M, Hiyaaki H, Miura S, Shibata H, Fujimoto M, Takeshita S, et al. Significance of trans-hepatic arterial chemotherapy for advanced hepatocellular carcinoma with portal vein tumor thrombus. Oncol Rep. 2008;20:353-7.

35. Kondo M, Morimoto M, Numata K, Nozaki A, Tanaka K. Hepatic arterial infusion therapy with a fine powder formulation of cisplatin for advanced hepatocellular carcinoma with portal vein tumor thrombosis. Jpn J Clin Oncol. 2011;41:69-75.

36. Chen SC, Lian SL, Chang WY. The effect of external radiotherapy in treatment of portal vein invasion in hepatocellular carcinoma. Cancer Chemother Pharmacol. 1994;33:S124-7.

37. Hata M, Tokuuye K, Sugahara S, Kagei K, Igaki H, Hashimoto T, et al. Proton beam therapy for hepatocellular carcinoma with portal vein tumor thrombus. Cancer. 2005;104:794-801.

38. Nakagawa K, Yamashita H, Shiraishi K, Nakamura N, Tago M, Igaki $\mathrm{H}$, et al. Radiation therapy for portal venous invasion by hepatocellular carcinoma. World J Gastroenterol. 2005;11:7237-41.

39. Zeng ZC, Fan J, Tang ZY, Zhou J, Qin LX, Wang JH, et al. A comparison of treatment combinations with and without radiotherapy for hepatocellular carcinoma with portal vein and/or inferior vena cava tumor thrombus. Int J Radiat Oncol Biol Phys. 2005;61:432-43.

40. Kim DY, Park W, Lim DH, Lee JH, Yoo BC, Paik SW, et al. Threedimensional conformal radiotherapy for portal vein thrombosis of hepatocellular carcinoma. Cancer. 2005;103:2419-26.

41. Lin CS, Jen YM, Chiu SY, Hwang JM, Chao HL, Lin HY, et al. Treatment of portal vein tumor thrombosis of hepatoma patients with either stereotactic radiotherapy or three-dimensional conformal radiotherapy. Jpn J Clin Oncol. 2006;36:212-7.

42. Zhang FJ, Li CX, Jiao DC, Zhang NH, Wu PH, Duan GF, et al. CT guided 125 iodine seed implantation for portal vein tumor thrombus in primary hepatocellular carcinoma. Chin Med J. 2008;121:2410-4.

43. Shirai S, Sato M, Suwa K, Kishi K, Shimono C, Kawai N, et al. Single photon emission computed tomography-based threedimensional conformal radiotherapy for hepatocellular carcinoma with portal vein tumor thrombus. Int J Radiat Oncol Biol Phys. 2009;73:824-31.

44. Giorgio A, di Sarno A, de Stafano G, Farella N, Scognamiglio U, de Stafeno M, et al. Hepatocellular carcinoma with cirrhosis: are patients with neoplastic main portal vein invasion eligible for percutaneous radiofrequency ablation of both the nodule and the portal venous tumor thrombus? AJR. 2009;193:948-54.

45. Lu ZH, Shen F, Yan LZ, Li J, Yang JH, Zong M, et al. Treatment of portal vein tumor thrombus of hepatocellular carcinoma with percutaneous laser ablation. J Cancer Res Clin Oncol. 2009; 135:783-9.

46. Kaneko S, Urabe T, Kobayashi K. Combination chemotherapy for advanced hepatocellular carcinoma complicated by major portal vein thrombosis. Oncology. 2002;62:69-73.

47. Sakon M, Nagano H, Dono K, Nakamori S, Umeshita K, Yamada A, et al. Combined intraarterial 5-fluorouracil and subcutaneous interferon- $\alpha$ therapy for advanced hepatocellular carcinoma with tumor thrombi in the major portal branches. Cancer. 2002;94:435-42.

48. Ishikura S, Ogino T, Furuse J, Satake M, Baba S, Kawashima M, et al. Radiotherapy after transcatheter arterial chemoembolization for patients with hepatocellular carcinoma and portal vein tumor thrombus. Am J Clin Oncol. 2002;25:189-93.

49. Yamada K, Izaki K, Sugimoto K, Mayahara H, Morita Y, Yoden E, et al. Prospective trial of combined transcatheter arterial chemoembolization and three-dimensional conformal radiotherapy for portal vein tumor thrombus in patients with unresectable hepatocellular carcinoma. Int J Radiat Oncol Biol Phys. 2003; 57:113-9. 
50. Ota H, Nagano H, Sakon M, Eguchi H, Kondo M, Yamamoto T, et al. Treatment of hepatocellular carcinoma with major portal vein thrombosis by combined with subcutaneous interferon- $\alpha$ and intra-arterial 5-fluorouracil; role of type 1 interferon receptor expression. Br J Cancer. 2005;93:557-64.

51. Hsu WC, Chan SC, Ting LL, Chung NN, Wang PM, Ying KS, et al. Results of three-dimensional conformal radiotherapy and thalidomide for advanced hepatocellular carcinoma. Jpn J Clin Oncol. 2006;36:93-9.

52. Obi S, Yoshida H, Toune R, Unuma T, Kanda M, Sato S, et al. Combination therapy of intraarterial 5-fluorouracil and systemic interferon-alpha for advanced hepatocellular carcinoma with portal venous invasion. Cancer. 2006;106:1990-7.

53. Ishikawa $\mathrm{T}$, Imai $\mathrm{M}$, Kamimura $\mathrm{H}$, Tsuchiya $\mathrm{A}$, Togashi $\mathrm{T}$, Watanabe $\mathrm{K}$, et al. Improved survival for hepatocellular carcinoma with portal vein tumor thrombosis treated by intra-arterial chemotherapy combining etoposide, carboplatin, epirubicin and pharmacokinetic modulating chemotherapy by $5-\mathrm{FU}$ and entericcoated tegafur/uracil: a pilot study. World J Gastroenterol. 2007;13:5465-70.

54. Kitamura Y, Aikata H, Takaki S, Kawaoka T, Waki K, Hiramatsu $\mathrm{A}$, et al. Intra-arterial 5-fluorouracil/interferon combination therapy for advanced hepatocellular carcinoma with or without three-dimensional conformal radiotherapy for portal vein tumor thrombosis. J Gastroenterol. 2009;44:492-502.

55. Zhang XB, Wang JH, Yan ZP, Qian S, Du SS, Zeng ZC. Hepatocellular carcinoma with main portal vein tumor thrombus. Treatment with 3-dimensional conformal radiotherapy after portal vein stenting and transarterial chemoembolization. Cancer. 2009;115:1245-52.

56. Luo JJ, Yan ZP, Liu QX, Qu XD, Wang JH. Endovascular placement of iodine 125 seed strand and stent combined with chemoembolization for treatment of hepatocellular carcinoma with tumor thrombus in main portal vein. J Vasc Interv Radiol. 2011;22:479-89.
57. Minagawa M, Makuuchi M, Takayama T, Ohtomo K. Selection criteria for hepatectomy in patients with hepatocellular carcinoma and portal vein tumor thrombus. Ann Surg. 2001;3:379-84.

58. Fan J, Wu ZQ, Tang ZY, Zhou J, Qiu SJ, Ma ZC, et al. Multimodality treatment in hepatocellular carcinoma with tumor thrombi in portal vein. World J Gastroenterol. 2001;7:28-32.

59. Fukuda S, Okuda K, Imamura M, Imamura I, Eriguchi N, Aoyagi S. Surgical resection combined with chemotherapy for advanced hepatocellular carcinoma with tumor thrombus: report of 19 cases. Surgery. 2002;131:300-10.

60. Lau WY, Ho SKW, Yu SCH, Lai ECH, Liew CT, Leung TWT. Salvage surgery following downstaging of unresectable hepatocellular carcinoma. Ann Surg. 2004;240:299-305.

61. Ku Y, Iwasaki T, Tominaga M, Fukumoto T, Takahashi T, Kido $\mathrm{M}$, et al. Reductive surgery plus percutaneous isolated hepatic perfusion for multiple advanced hepatocellular carcinoma. Ann Surg. 2004;239:53-60.

62. Nagano H, Miyamoto A, Wada H, Ota H, Marubashi S, Takeda $\mathrm{Y}$, et al. Interferon- $\alpha$ and 5-fluorouracil combination therapy after palliative hepatic resection in patients with advanced hepatocellular carcinoma, portal venous tumor thrombus in the major trunk, and multiple nodules. Cancer. 2007;110:2493-501.

63. Kamiyama T, Nakanishi K, Yokoo H, Tahara M, Nakagawa T, Kamachi $\mathrm{H}$, et al. Efficacy of preoperative radiotherapy to portal vein tumor thrombus in the main trunk or first branch in patients with hepatocellular carcinoma. Int J Clin Oncol. 2007;12:363-8.

64. Peng BG, He Q, Li JP, Zhou F. Adjuvant transcatheter arterial chemoembolization improves efficacy of hepatectomy for patients with hepatocellular carcinoma and portal vein tumor thrombus. Am J Surg. 2009;198:313-8. 